\title{
Density of soil composition using various methods of processing crops of spring wheat in the conditions of the Republic of Tatarstan
}

\author{
M. R. Akhmetzyanov*, I. P. Talanov, I. G. Manyukova \\ Kazan State Agrarian University, 420015 Kazan, Russia
}

\begin{abstract}
The article presents results of the study of the soil density composition and the yield of spring wheat grain depending on the methods of processing gray forest soil of the Republic of Tatarstan. The high density of soil composition among all the options is the option with direct sowing in the $0-10 \mathrm{~cm}$ layer of $1.18 \mathrm{~g} / \mathrm{cm}^{3}$, in the $10-20 \mathrm{~cm}$ layer $-1.27 \mathrm{~g} / \mathrm{cm}^{3}$. In the options for stubble plowing with subsequent plowing the indicators were 1.13 and $1.22 \mathrm{~g} / \mathrm{cm}^{3}$, respectively. By the phase of getting into the tube and before harvesting spring wheat, the soil bulk density increased in all variants of soil cultivation. The minimum values of the soil bulk density were noted for the options "stubble cultivation + plowing" and amounted to 1.18 and $1.26 \mathrm{~g} / \mathrm{cm}^{3}$ in the $0-10 \mathrm{~cm}$ layer, 1.27 and $1.30 \mathrm{~g} \mathrm{/} \mathrm{cm}$ in the $10-20 \mathrm{~cm}$ layer. In the variant with direct sowing, these indicators were 1.25 and $1.31 \mathrm{~g} / \mathrm{cm}^{3}$ in the $0-10 \mathrm{~cm}$ layer, 1.32 and $1.36 \mathrm{~g}$ $/ \mathrm{cm}^{3}$ in the 10-20 cm layer. In a layer of $10-20 \mathrm{~cm}$, the density of soil composition, depending on the methods of tillage, increased to $1.27-1.32 \mathrm{~g} / \mathrm{cm}^{3}$, before harvesting $-1.30-1.35 \mathrm{~g} / \mathrm{cm}^{3}$, while the regularity between control and direct sowing have been preserved. The maximum grain yield ( $3.59 \mathrm{t} / \mathrm{ha})$ and high economic efficiency of spring wheat cultivation were obtained from the use of shallow loosening of the soil with a KSN-3 unit in combination with loosening after a year.
\end{abstract}

\section{Introduction}

Edaphic factors, including those associated with the complex of agrophysical properties of the soil, are of particular importance in the formation of the yield of the main agricultural crops. The most important indicator that determines the agrophysical parameters of the soil and its effect on the productivity of plants is the bulk density $[1,2]$.

The bulk mass of the soddy-medium podzolic light loamy soil of the Republic of Tatarstan is $1.31 \mathrm{~g} / \mathrm{cm} 3-$ $1.51 \mathrm{~g} / \mathrm{cm} 3$, and the gray forest soil of heavy loamy granulometric composition is $1.45 \mathrm{~g} / \mathrm{cm} 3-1.57 \mathrm{~g} / \mathrm{cm} 3$ (optimal values for loamy soils $1.0-1.3 \mathrm{~g} / \mathrm{cm} 3$ ), i.e. has an unsatisfactory assessment. Therefore, the problem of soil overconsolidation is one of the main problems in agriculture and requires the development of scientifically based approaches to its solution [3].

The world community recognized the need to protect soil and identified soil compaction as one of the main threats that can lead to its degradation [4]. All this contributed to the growth of attention to this problem both on the part of scientists and representatives of the agricultural sector, and on the part of state bodies.

The reasons for the increase in soil degradation due to steel compaction are the increase in the weight of agricultural machinery, with more intensive use of widecut machines; violation of the basic elements of farming systems (lack of crop rotation, irrational system of soil cultivation, minimal use of organic fertilizers, etc.), global climate change, etc.

According to the State Report "On the State of Natural Resources and on Environmental Protection of the Republic of Tatarstan in 2016" [5,6], the bulk mass of the soddy-medium podzolic light loamy soil is $1.31 \mathrm{~g}$ $/ \mathrm{cm} 3-1.51 \mathrm{~g} / \mathrm{cm} 3$, and the gray forest soils of heavy loamy granulometric composition - $1.45 \mathrm{~g} / \mathrm{cm} 3-1.57 \mathrm{~g}$ / cm3 (optimal values for loamy soils $1.0-1.3 \mathrm{~g} / \mathrm{cm} 3$ ), i.e. it has an unsatisfactory assessment. Therefore, the problem of soil overconsolidation is one of the main in agriculture in Tatarstan and requires the development of scientifically based approaches to its solution [7].

Soil compaction is an extremely acute environmental problem [8]. This is one of the main causes of water erosion and flooding (plant hypoxia) [9]. In addition, this process directly or indirectly increases the leaching of nutrients and pesticides into groundwater and increases the emission of carbon dioxide and nitrous oxide (greenhouse gases) into the atmosphere [10].

All this determines the need for the development of scientifically based approaches to the regulation of soil compaction to maintain its fertility and sustainable cultivation of spring wheat. 


\section{Research Objective}

To achieve the goal of the research, we carried out a study of the density of the soil composition of the hardness of the arable layer of soil under crops of spring wheat (the predecessor of spring rapeseed), depending on the methods of tillage in the conditions of the gray forest soil of the Republic of Tatarstan.

Characteristics of the experimental plot: gray forest soil, medium loamy, arable layer thickness of 24-25 cm, salt extract pH 5.7; hydrolytic acidity $-5.07 \mathrm{mg} /$ eq., the amount of absorbed bases - $20.79 \mathrm{mg} / \mathrm{eq}$; the degree of saturation with bases - 80.39\%; humus content (according to Tyurin) - 3.59\%; the content of mobile forms of phosphorus and exchangeable potassium 15.6 and $7.8 \mathrm{mg}$ per $100 \mathrm{~g}$ of soil; the content of easily hydrolyzable nitrogen is $18.2 \mathrm{mg}$ per $100 \mathrm{~g}$ of soil.

\section{Experimental scheme and agricultural technology}

In order to study the possibility of minimizing the main tillage on gray forest soils, we laid a field experiment with spring wheat in 2014-2016.

Experiment scheme:

1. Peeling + plowing (control).

2. Shallow by $10-12 \mathrm{~cm} \mathrm{KSN-3}$ with periodic moldless loosening to a depth of 23-25 PN-4-35 with SIBIME racks (shallow).

3. Small by $10-12 \mathrm{~cm} \mathrm{KSN-3,} \mathrm{constant.}$

4. Surface by $6-8 \mathrm{~cm}$ BDT-3 with periodic moldless loosening to a depth of $23-25 \mathrm{~cm}$, after 1 year.

5. Surface (BDT-3), constant.

6. Direct seeding.

\section{Results}

The bulk density before sowing spring wheat in the 0-10 $\mathrm{cm}$ layer according to the experimental options varied within 1.13-1.18 g / cm3, and high rates both in the 0-10 $\mathrm{cm}$ layer and in the 10-20 cm layer $(1,18 / 1.27 \mathrm{~g} / \mathrm{cm} 3)$ had surface methods of tillage (Table 1).

An increase in soil compaction density indicators occurred in the phase of entering the tube, in the $0-10 \mathrm{~cm}$ layer on the control it was $1.18 \mathrm{~g} / \mathrm{cm} 3$; then on the direct sowing option it reached $1.25 \mathrm{~g} / \mathrm{cm} 3$, and on other soil tillage options it was $1,19-1.23 \mathrm{~g} / \mathrm{cm} 3$. In a layer of $10-20 \mathrm{~cm}$, the density of soil composition, depending on the methods of tillage, increased to 1.27$1.32 \mathrm{~g} / \mathrm{cm} 3$, while the regularity between the control and direct sowing remained the same. By the time of harvest, further compaction of the arable soil layer took place in the $0-10 \mathrm{~cm}$ layer $1.26-1.31 \mathrm{~g} / \mathrm{cm} 3$, in the 10 $20 \mathrm{~cm}$ layer - 1.30-1.35 g/ cm3, but did not go beyond the indicators $(1.40 \mathrm{~g} / \mathrm{cm} 3)$ when the use of nutrients and moisture by the root system is significantly hampered.

Consequently, options with moldboard main tillage reduce the density of the soil composition, surface increase soil compaction, and direct sowing without tillage increased soil density during the growing season.

Indicators of the hardness of the arable layer varied depending on the moisture content, biological characteristics, depth and methods of soil cultivation (Table 2). Deep tillage (plowing, moldboard-free loosening) reduces soil hardness compared to shallow and shallow soil ones.

So, on average for three years, soil hardness before sowing spring wheat: in the $0-10 \mathrm{~cm}$ layer of halfcultivation + plowing and shallow (KSN-3), loosening after 1 year was $12.9-13.5 \mathrm{~kg} / \mathrm{cm}^{2}$; on the surface ( BDT-3), loosening after 1 year and superficial (BDT-3), constant -16.1 and $15.3 \mathrm{~kg} / \mathrm{cm}^{2}$.

A similar but more pronounced difference was observed in the layer $10-20 \mathrm{~cm}-19.1 \mathrm{~kg} / \mathrm{cm}^{2}$ plowing and $25.7 \mathrm{~kg} / \mathrm{cm}^{2}$ on the surface. In the $10-20 \mathrm{~cm}$ layer, the soil hardness increased in all the options, but the difference between the options was not as pronounced as in the $0-10 \mathrm{~cm}$ layer.

In general, during the growing season of spring wheat, a comparatively lower hardness of the arable soil layer was noted in the option with plowing. Moreover, by the end of the growing season, soil hardness in all variants of the experiment, increased both in the upper and in the lower layers, but went beyond the recommended limits $(40 \mathrm{~kg} / \mathrm{cm} 2)$ for the cultivation of spring wheat.

Consequently, the options with stubble plowing and moldboard main tillage and shallow loosening (KSN-3) reduced the soil hardness indices after a year, while the surface ones slightly increased these indices.

Accounting the yield of spring wheat, depending on the methods of basic tillage, showed that its maximum values were observed when conducting shallow loosening of the soil with a KSN-3 unit with periodic non-moldboard loosening to a depth of 23-25 PN-4-35 with SIBIME stands and amounted to $3.59 \mathrm{t} / \mathrm{ha}$, while in other variants they were 3.37-2.72 $\mathrm{t} / \mathrm{ha}$, which is significantly lower than the least significant difference (LSD) (Table 2). 
Table 1. Dynamics of soil composition density depending on technologies of spring wheat cultivation, 2014-2016, g / cm3.

\begin{tabular}{|c|c|c|c|c|c|c|c|c|c|c|}
\hline \multirow{4}{*}{ No. } & \multirow{4}{*}{ Processing options } & \multicolumn{9}{|c|}{ Terms of determination } \\
\hline & & \multicolumn{3}{|c|}{ Before sowing } & \multicolumn{3}{|c|}{ Tube exit phase } & \multicolumn{3}{|c|}{ Before cleaning } \\
\hline & & $0-10$ & $10-20$ & $0-20$ & $0-10$ & $10-20$ & $0-20$ & $0-10$ & $10-20$ & $0-20$ \\
\hline & & $\mathrm{cm}$ & $\mathrm{cm}$ & $\mathrm{cm}$ & $\mathrm{cm}$ & $\mathrm{cm}$ & $\mathrm{cm}$ & $\mathrm{cm}$ & $\mathrm{cm}$ & $\mathrm{cm}$ \\
\hline 1. & $\begin{array}{l}\text { Peeling }+ \text { plowing } \\
\text { (control) }\end{array}$ & 1.13 & 1.22 & 1.18 & 1.18 & 1.27 & 1.23 & 1.26 & 1.30 & 1.28 \\
\hline 2. & $\begin{array}{l}\text { Fine (KSN-3), loosening } \\
\text { after } 1 \text { year }\end{array}$ & 1.14 & 1.22 & 1.18 & 1.20 & 1.29 & 1.25 & 1.27 & 1.31 & 1.29 \\
\hline 3. & Fine (KSN-3), constant & 1.15 & 1.24 & 1.20 & 1.20 & 1.30 & 1.25 & 1.28 & 1.33 & 1.31 \\
\hline 4. & $\begin{array}{l}\text { Surface (BDT-3), } \\
\text { loosening after } 1 \text { year }\end{array}$ & 1.15 & 1.23 & 1.19 & 1.20 & 1.30 & 1.25 & 1.28 & 1.32 & 1.30 \\
\hline 5. & Surface (BDT-3), constant & 1.15 & 1.26 & 1.21 & 1.23 & 1.32 & 1.28 & 1.29 & 1.35 & 1.32 \\
\hline 6 & Direct seeding & 1.18 & 1.27 & 1.23 & 1.25 & 1.32 & 1.29 & 1.31 & 1.36 & 1.34 \\
\hline
\end{tabular}

Table 2. Influence of basic tillage methods on soil hardness under crops of spring wheat, $\mathrm{kg} / \mathrm{cm} 2,2014-2016$

\begin{tabular}{|l|c|c|c|c|c|c|c|c|}
\hline \multirow{2}{*}{ Processing options } & \multicolumn{3}{|c|}{ Before sowing } & \multicolumn{3}{c|}{ Before cleaning } \\
\cline { 2 - 9 } & $0-10 \mathrm{~cm}$ & $\begin{array}{c}10-20 \\
\mathrm{~cm}\end{array}$ & $\begin{array}{c}20-30 \\
\mathrm{~cm}\end{array}$ & $0-30 \mathrm{~cm}$ & $0-10 \mathrm{~cm}$ & $\begin{array}{c}10-20 \\
\mathrm{~cm}\end{array}$ & $\begin{array}{c}20-30 \\
\mathrm{~cm}\end{array}$ & $0-30 \mathrm{~cm}$ \\
\hline $\begin{array}{l}\text { Peeling + plowing } \\
\text { (control) }\end{array}$ & 12.9 & 21.0 & 36.0 & 23.3 & 20.8 & 32.9 & 39.4 & 31.0 \\
\hline $\begin{array}{l}\text { Fine (KSN-3), } \\
\text { loosening after 1 year }\end{array}$ & 13.5 & 25.2 & 36.7 & 25.1 & 22.1 & 33.8 & 40.2 & 32.0 \\
\hline Fine (KSN-3), constant & 14.4 & 27.3 & 38.0 & 26.6 & 23.4 & 34.0 & 42.8 & 33.4 \\
\hline $\begin{array}{l}\text { Surface (BDT-3), } \\
\text { loosening after 1 year }\end{array}$ & 16.1 & 29.3 & 39.1 & 28.2 & 25.3 & 37.1 & 44.3 & 35.6 \\
\hline Surface (BDT-3), & 15.3 & 26.9 & 37.2 & 25.5 & 22.9 & 35.2 & 42.5 & 33.9 \\
\hline constant & 14.6 & 25.7 & 38.1 & 26.1 & 23.4 & 36.4 & 43.4 & 34.4 \\
\hline Direct seeding
\end{tabular}

The same variant showed comparatively better indicators of the economic efficiency of various methods of basic tillage. The cost price of 1 centner of grain when carrying out shallow loosening of the soil using the KSN-3 unit in combination with moldboard loosening to a depth of 23-25 PN-4-35 with SIBIME stands by loosening was 407.1 rubles, the profitability was $72 \%$, while for plowing these indicators were 454.7 rubles and $54 \%$.

The economic indicators of other shallow and surface tillage and direct sowing were significantly lower than in the variant with the use of shallow loosening of the soil with the KSN-3 unit in combination with loosening the soil after a year. 
Table 3. Yield and economic efficiency of spring wheat, 2014-2016

\begin{tabular}{|c|l|c|c|c|c|c|c|}
\hline No. & \multicolumn{1}{|c|}{ Processing options } & $\begin{array}{c}\text { Productivity, } \mathrm{t} \\
/ \text { ha }\end{array}$ & $\begin{array}{c}\text { The cost of } \\
\text { gross } \\
\text { production, } \\
\text { rubles / ha }\end{array}$ & $\begin{array}{c}\text { Production } \\
\text { costs, rubles } \\
\text { / ha }\end{array}$ & $\begin{array}{c}\text { Cost of 1 } \\
\text { centner of } \\
\text { grain, rub. }\end{array}$ & $\begin{array}{c}\text { Conditional } \\
\text { net income } \\
\text { per hectare, } \\
\text { rubles }\end{array}$ & $\begin{array}{c}\text { Profitability } \\
\text { level, } \%\end{array}$ \\
\hline 1. & $\begin{array}{l}\text { Peeling + plowing } \\
\text { (control) }\end{array}$ & 3.33 & 23310 & 15141.0 & 454.7 & 8169.0 & 54.0 \\
\hline 2. & $\begin{array}{l}\text { Fine (KSN-3), } \\
\text { loosening after 1 year }\end{array}$ & 3.59 & 25130 & 14616.0 & 407.1 & 10514.0 & 72.0 \\
\hline 3. & $\begin{array}{l}\text { Fine (KSN-3), } \\
\text { constant }\end{array}$ & 3.05 & 21350 & 14017.5 & 459.6 & 7332.5 & 52.3 \\
\hline 4. & $\begin{array}{l}\text { Surface (BDT-3), } \\
\text { loosening after 1 year }\end{array}$ & 3.37 & 23590 & 14574.0 & 432.5 & 9016.0 & 61.9 \\
\hline 5. & $\begin{array}{l}\text { Surface (BDT-3), } \\
\text { constant }\end{array}$ & 2.94 & 20580 & 13975.5 & 475.4 & 6604.5 & 47.3 \\
\hline 6 & Direct seeding & 2.72 & 19740 & 12122.5 & 429.8 & 7617.5 & 62.8 \\
\hline
\end{tabular}

$\mathrm{LSD}_{05} 0,82$

\section{Conslusion}

For deep tillage (plowing, moldless loosening) in comparison with shallow and surface tillage, the bulk density and hardness were used in an optimal ratio. The best method for shaping the yield of spring wheat turned out to be the use of shallow loosening of the soil with a KSN-3 unit in combination with loosening a year later and amounted to $3.59 \mathrm{t} / \mathrm{ha}$, against $3.33 \mathrm{t} /$ ha using traditional plowing and 2.94-3.37 t / ha by conducting small, surface treatments and direct sowing of spring wheat. In the same variant, the economic indicators were higher than in the variants for using moldboard plowing and various methods of shallow and surface treatments.

\section{References}

1. A.G. Bondarev, Physical properties of soils as a theoretical basis for predicting their compaction, in: Influence of agricultural machinery on the soil, pp. 80-85 (Nauka, Moscow, 1981)

2. A.N. Chervan, V.B. Tsyribko, A.M. Ustinova, Data of agrophysical properties of soils in the formation of soil-protective systems of agriculture using Gistechnologies on the example of the Braslav district of the Vitebsk region, Soil Science and Agrochemistry, 1(56), 25-36 (2016)

3. State report "On the state of natural resources and on environmental protection of the Republic of Tatarstan in 2016" (Ministry of Ecology and Natural Resources of the Republic of Tatarstan, Kazan) 508 p.

4. COM (Commission of the European Communities). Communication from the Commission to the
Council, the European Parliament, the Economic and Social Committee and the Committee of the Regions - Towards a Thematic Strategy for Soil Protection, p. 35 (Brussels, 2002)

5. State report "On the state of natural resources and on environmental protection of the Republic of Tatarstan in 2016" (Ministry of Ecology and Natural Resources of the Republic of Tatarstan, Kazan) 508 p.

6. N.L. Kurachenko, A.A. Lelyakova, Influence of the main processing on the agrophysical parameters of chernozems of the Krasnoyarsk forest-steppe, Bulletin of the Buryat State Agricultural Academy named after V.R. Filippov, 4, 26-32 (2012)

7. I.G. Gilaev, R.M. Sabirova, R.S. Shakirov, Yield and quality of spring wheat grain with different fertilization systems and methods of basic soil cultivation, in: Modern technologies of growing agricultural crops: Materials of the All-Russian scientific-practical conference of young scientists dedicated to the memory of Gareeva R. G., pp. 189197 (2015)

8. M. Pagliai, N. Vignozzi, S. Pellegrini, Soil structure and the effect of management practices, Soil and Tillage Research, 79, 131-143 (2004)

9. M. Gieska, R.R. van der Ploeg, P. Schweigert, N. Pinter, Physikalische Bodendegradierung in der Hildesheimer Börde und das BundesBodenschutzgesetz, Berichteüber Landwirtschaft, 81, 485-511 (2003)

10. C. Bessou, J. Mary, M. Léonard, E. Roussel, B. Gréhan, Modeling soil compaction impacts on nitrous oxide emissions in arable fields, European Journal of Soil Science, 61, 348-363 (2010) 